Check for updates

Cite this: RSC Adv., 2019, 9, 32066

\title{
Optimization of the electron transport in quantum dot light-emitting diodes by codoping ZnO with gallium (Ga) and magnesium (Mg) $\uparrow$
}

\begin{abstract}
Hong Hee Kim, $\xi^{\text {ab }}$ David O. Kumi,,$^{\mathrm{c}}$ Kiwoong Kim, ${ }^{d}$ Donghee Park, ${ }^{a}$ Yeonjin Yi, ${ }^{d}$ So Hye Cho, (D) e Cheolmin Park, (D) ${ }^{b}$ O. M. Ntwaeaborwa*c and Won Kook Choi (D) *a

In our study, to optimize the electron-hole balance through controlling the electron transport layer (ETL) in the QD-LEDs, four materials ( $\mathrm{ZnO}, \mathrm{ZnGaO}, \mathrm{ZnMgO}$, and $\mathrm{ZnGaMgO}$ NPs) were synthesized and applied to the QD-LEDs as ETLs. By doping ZnO NPs with Ga, the electrons easily inject due to the increased Fermi level of ZnO NPs, and as Mg is further doped, the valence band maximum (VBM) of ZnO NPs deepens and blocks the holes more efficiently. Also, at the interface of QD/ETLs, Mg reduces non-radiative recombination by reducing oxygen vacancy defects on the surface of ZnO NPs. As a result, the maximum luminance $\left(L_{\max }\right)$ and maximum luminance efficiency $\left(L E_{\max }\right)$ of QD-LEDs based on $Z n G a M g O$ NPs reached $43440 \mathrm{~cd} \mathrm{~m}^{-2}$ and $15.4 \mathrm{~cd} \mathrm{~A}^{-1}$. These results increased by $34 \%, 10 \%$ and $27 \%$ for the $L_{\max }$ and $450 \%, 88 \%$, and $208 \%$ for the $\mathrm{LE}_{\max }$ when compared with $\mathrm{ZnO}, \mathrm{ZnGaO}$, and $\mathrm{ZnMgO}$ NPs as ETLs.
\end{abstract}

Received 2nd September 2019 Accepted 29th September 2019

DOI: $10.1039 / c 9 r a 06976 c$

rsc.li/rsc-advances

previous studies. ${ }^{9}$ The defects easily quench excitons at the $\mathrm{ZnO}$ NPs/QDs interface because the charge transfer between the interfaces is disturbed and non-radiative recombination takes place. ${ }^{7,8}$ The low valence energy level of un-doped $\mathrm{ZnO}$ restrains the performance of QD-based LEDs due to lack of sufficient hole blocking at the deep valence energy level of QDs. ${ }^{9}$

To address this problem, Yang et al. ${ }^{10}$ proposed doping ZnO NPs with an inorganic II-element, $\mathrm{Mg}$, which effectively improved the charge balance and inhibited exciton quenching of the QD-LEDs. The conduction band minimum (CBM) energy levels of Mg-doped ZnO NPs was systematically closer to the vacuum level with increasing $\mathrm{Mg}$ content. ${ }^{6} \mathrm{Ga}$ also attenuated the charge transfer at the interface between Ga-doped ZnO NPs/ QDs because the Fermi level of ZnO NPs was increased by the (increment of) Ga dopants. ${ }^{5}$ However, these studies were also not sufficient to promote charge transfer in QD-LEDs, indicating that a single dopant is not effective.

Herein, we propose multiple dopants to optimize the electron-hole balance through controlling ETL in the QD-LEDs. GaMg-codoped ZnO NPs were synthesized and applied to QD-LEDs in comparison with $\mathrm{ZnO}-$, ZnGaO (ZGO)-, and $\mathrm{ZnMgO}$ (ZMO)based QD-LEDs. Fundamental properties of ZnGaMgO (ZGMO) based QD-LEDs were studied to optimize the charge balance, followed by the discussion about roles of each doping elements in terms of the band theory. When Ga is doped into ZnO NPs, the Fermi level of ZnO increases, thereby making the injection of electrons easier. In addition, $\mathrm{Mg}$ codoping deepens the valence band maximum (VBM) and block hole migration more efficiently. As a consequence, by codoping $\mathrm{Ga}$ and $\mathrm{Mg}$ elements $(10 \% \mathrm{Ga}$ and $3 \% \mathrm{Mg})$ into ZnO NPs to optimize the charge balance of the QD-LEDs. The performance of QD-LEDs 
with ETL consisting of ZGMO NPs indicated a maximum luminance $\left(L_{\max }\right)$ of $43440 \mathrm{~cd} \mathrm{~m}^{-2}$ at $7 \mathrm{~V}$ and a maximum luminance efficiency ( $\mathrm{LE}_{\max }$ ) of $15.4 \mathrm{~cd} \mathrm{~A}^{-1}$ at $4.5 \mathrm{~V}$. In addition, when applying ZnO, ZGO, and ZMO as ETL to QD-LEDs, the $L_{\max }$ was 32480 (@7 V), 39630 (@7 V), and 34090 (@ 7 V) cd m², respectively, and the max. LE was respectively 2.8 (@ $4.5 \mathrm{~V}$ ), 8.2 (@ $5 \mathrm{~V}$ ), and 5.0 (@ $5.5 \mathrm{~V}$ ) cd $\mathrm{cd}^{-1}$. When these results comparing these results with the results of ZGMO as ETL, the $L_{\max }$ is increased by $34 \%, 10 \%$, and $27 \%$, respectively, while $\mathrm{LE}_{\max }$ is increased by $450 \%, 88 \%$ and $208 \%$, respectively.

\section{Experimental procedure}

\section{Chemicals}

Zinc acetate $\left(\mathrm{Zn}\left(\mathrm{CH}_{3} \mathrm{COO}\right)_{2}\right)$, magnesium acetate tetrahydrate $\left(\mathrm{Mg}\left(\mathrm{CH}_{3} \mathrm{COO}\right)_{2} \cdot 4 \mathrm{H}_{2} \mathrm{O}\right)$, gallium(III) triacetate $\left(\mathrm{Ga}\left(\mathrm{CH}_{3} \mathrm{COO}\right)_{3}\right)$, dimethyl sulfoxide (DMSO), and tetramethylammonium hydroxide (TMAH) were purchased from Sigma-Aldrich. Poly(3,4-ethylenedioxythiophene):polystyrene sulfonate (PEDOT:PSS, AI 4083) was purchased from Heraeus. Poly $\left(N, N^{\prime}-\right.$ bis(4-butylphenyl)- $N, N^{\prime}$-bis(phenyl)benzidine) (poly-TPD) was purchased from American Dye Source (ADS), Inc. Alloyed CdSe/ ZnS QDs (Green QDs) were purchased from ZEUS Ltd.

\section{Synthesis of ZnO, ZnGaO, ZnMgO, and ZnGaMgO NPs}

ZnO NPs were synthesized using the precipitation-solution method as reported in our previous work. ${ }^{11}$ TMAH (0.9062 g) was completely dissolved in $10 \mathrm{ml}$ of ethanol at room temperature. Then, the solution was slowly injected into a $30 \mathrm{ml}$ DMSO dissolved in zinc acetate $(0.5503 \mathrm{~g})$ for $1 \mathrm{~h}$ with a magnetic stirrer. Finally, the resultant ZnO NPs were washed with acetone and dispersed in ethanol $\left(\sim 30 \mathrm{mg} \mathrm{ml}^{-1}\right)$. The above procedure was repeated for the synthesis of $\mathrm{ZnGaO}$ (gallium(III) triacetate, $0.1 \mathrm{mmol}$ ), ZnMgO (magnesium acetate tetrahydrate, 0.13 $\mathrm{mmol}$ ), and ZnGaMgO (gallium(III) triacetate, $0.1 \mathrm{mmol}$ and magnesium acetate tetrahydrate, $0.04 \mathrm{mmol}$ ) using the appropriate stoichiometry.

\section{Fabrication of QD-LEDs device}

QD-LED devices were fabricated on patterned indium-tin-oxide (ITO) glass substrates. The substrates were ultrasonic-cleaned using acetone, ethanol, and deionized water for $15 \mathrm{~min}$ and then treated with ultraviolet (UV)-Ozone for $15 \mathrm{~min}$. PEDOT:PSS was spin-coated on the ITO glass substrates at $4000 \mathrm{rpm}$ for $40 \mathrm{~s}$ and baked at $130{ }^{\circ} \mathrm{C}$ for $30 \mathrm{~min}$. The ITO glass substrates were transferred to a nitrogen glove box where the remaining fabrication steps were carried out. Poly-TPD was spin-coated on top of PEDOT:PSS layer at $5000 \mathrm{rpm}$ for $40 \mathrm{~s}$ and annealed at $130{ }^{\circ} \mathrm{C}$ for $30 \mathrm{~min}$, followed by spin-coating of Green QD layer on the top of it and subsequent annealing at $90{ }^{\circ} \mathrm{C}$ for $30 \mathrm{~min}$. ETL of ZnO, ZGO, ZMO, ZGMO NPs were deposited on the Green QD layer using spin-coating technique at $3000 \mathrm{rpm}$ for $40 \mathrm{~s}$ and baked at $140{ }^{\circ} \mathrm{C}$ for $30 \mathrm{~min}$. Finally, an $\mathrm{Al}$ cathode film $(120 \mathrm{~nm})$ was deposited by thermal evaporation through a patterned shadow mask.

\section{Fabrication of QD-LEDs device}

Synthesized ZnO, ZnGO, ZMO, and ZGMO were analysed using the following characterization techniques: the physical properties (structure and particle morphology) were measured with XRD (RIGAKU D/Max 2500, Cu K $\alpha, \lambda=0.154$ $\mathrm{nm}$ ) and TEM (TITAN (TM80-300)). The optical properties were measured with a PerkinElmer Lambda 750 UV/VIS/NIR spectrometer and Jasco FP-8500 Spectrofluorometer. The surface chemical composition and binding energy of the constitutional elements were examined by the X-ray Photoelectron Spectroscopy (XPS) (ULVAC PHI 5000 Versa Probe system, $\mathrm{Al} \mathrm{K} \alpha, h v=1486.6 \mathrm{eV})$. The Fermi level and work function of the ZnO NPs were determined utilizing ultraviolet photoelectron spectroscopy (UPS) (ULVAC PHI 5000 Versa Probe, helium discharge lamp, $h \nu=21.22 \mathrm{eV}$ ). The currentvoltage-luminance characteristics of the devices were measured with a Spectra Scan PR-670 spectroradiometer and a Keithley-2400 source-measure unit.

\section{Results and discussion}

QD-LEDs with various concentrations were fabricated to control the energy level of ETL in the QD-LEDs. XPS results in Table 1 (see the ESI $\dagger$ ) confirmed the relative atomic ratio between the elements of each specimen: $\mathrm{ZnO}, \mathrm{Zn}_{0.88} \mathrm{Ga}_{0.12} \mathrm{O}, \mathrm{Zn}_{0.86} \mathrm{Mg}_{0.14} \mathrm{O}$, and $\mathrm{Zn}_{0.87} \mathrm{Ga}_{0.1} \mathrm{Mg}_{0.03} \mathrm{O}$, indicating that $\mathrm{Ga}$ and/or $\mathrm{Mg}$ were successfully incorporated into ZnO NPs. The XRD results of ZnO, ZGO, ZMO, and ZGMO NPs in Fig. 1(a) clearly showed peaks of a wurtzite hexagonal ZnO structure: (100), (002), (101), (102), (110), (103), and (112), ruling out the formation of phase- (a)

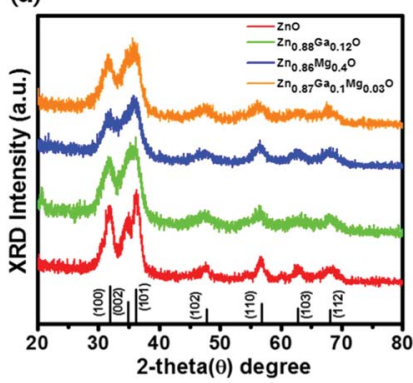

(c)

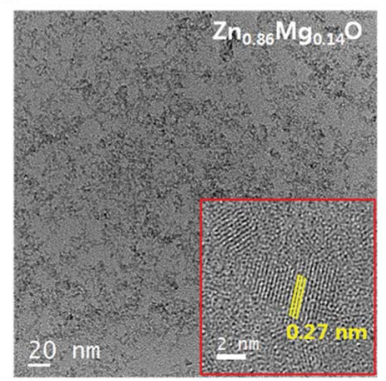

(b)

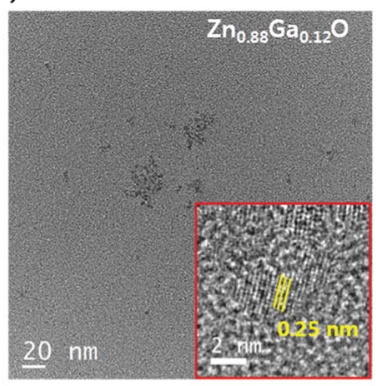

(d)

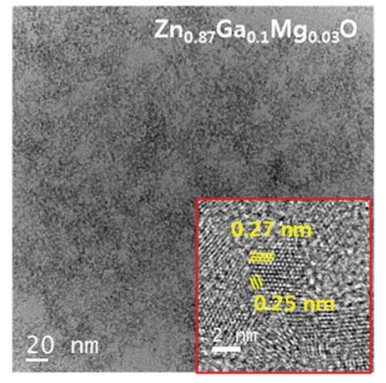

Fig. 1 (a) XRD patterns of $\mathrm{ZnO}, \mathrm{ZnGaO}, \mathrm{ZnMgO}$, and $\mathrm{ZnGaMgO}$. (b), (c), and (d) TEM images of $\mathrm{ZnGaO}, \mathrm{ZnMgO}$, and $\mathrm{ZnGaMgO}$, respectively. The insets in (b, $c$, and d) show the HRTEM images and crystal lattice planes with $d$-spacing. 
separated corundum type $\mathrm{Ga}_{2} \mathrm{O}_{3}$ and cubic $\mathrm{MgO}$. All the other observed XRD peaks were weak and broad with increasing doping ratio of $\mathrm{Ga}$ and/or $\mathrm{Mg}$, suggesting that the particle sizes of ZGO and ZMO, and ZGMO NPs are smaller than those of ZnO. The XRD peak broadening is therefore the result of the nanosize effect. ${ }^{12}$ Fig. 1(b)-(d) show characteristic transmission electron microscopy (TEM) and high-resolution TEM (HRTEM) images of $\mathrm{ZnO}$, ZnGaO, ZnMgO, and ZnGaMgO NPs. As shown in the insets, the inter-planar spacings of $0.25 \mathrm{~nm}$ and $0.27 \mathrm{~nm}$ of crystal lattice fringes correspond to (100) lattice plane of $\mathrm{ZnO}$ NPs ${ }^{13}$ which is inconsistent with any inter-planar spacing of $\mathrm{Ga}_{2} \mathrm{O}_{3}$ or $\mathrm{MgO}$ (slightly different to each other. Additional information is available in Fig. $\mathrm{S} 1, \mathrm{ESI} \dagger)$. Since the radii of $\mathrm{Ga}^{3+}$ $(0.62 \AA)$ and $\mathrm{Mg}^{2+}(0.74 \AA)$ are similar to that of $\mathrm{Zn}^{2+}(0.72 \AA),{ }^{14}$ $\mathrm{Ga}$ and $\mathrm{Mg}$ doping results in the formation of substitutional solid reaction without appreciable strain and thus only slightly increase and decrease of inter-planar spacing, respectively. This is consistent with the previous observation that the covalent bond length of Ga-O $(1.92 \AA)$ is more slightly shorter and that of $\mathrm{Mg}-\mathrm{O}(2.06 \AA)$ is more slightly longer than that of $\mathrm{Zn}-\mathrm{O}(1.97 \AA)$. However, the reason for this is not clear yet and further investigation is necessary. Fig. 2 shows XPS spectra of ZnO, ZGO, ZMO, and ZGMO NPs that also confirm the presence of $\mathrm{Zn}, \mathrm{Ga}$, and $\mathrm{Mg}$ elements in the NPs. Fig. 2(b) presents the highresolution Zn 2p XPS spectra of each phase. As for ZnO NPs, the two peaks measured at $1044.41 \mathrm{eV}$ and $1021.32 \mathrm{eV}$ are attributed to the spin-orbit splitting $\left(\Delta E_{\mathrm{SO}}=23.09 \mathrm{eV}\right)$ of $\mathrm{Zn}$ $2 \mathrm{p}_{1 / 2}$ and $\mathrm{Zn} 2 \mathrm{p}_{3 / 2}$ core levels, respectively. $\mathrm{Zn} 2 \mathrm{p}_{1 / 2}$ and $\mathrm{Zn} 2 \mathrm{p}_{3 / 2}$ peaks of ZGO, ZMO, and ZGMO NPs are $1044.46 \mathrm{eV}, 1044.62 \mathrm{eV}$, $1045.01 \mathrm{eV}$ and $1021.38 \mathrm{eV}, 1021.51 \mathrm{eV}$, and $1021.93 \mathrm{eV}$, respectively and their $\Delta E_{\mathrm{SO}}$ 's are almost the same. The observed Zn 2p peak shifted toward slightly higher binding energies of doped ZnO NPs and this is believed to be a result of the
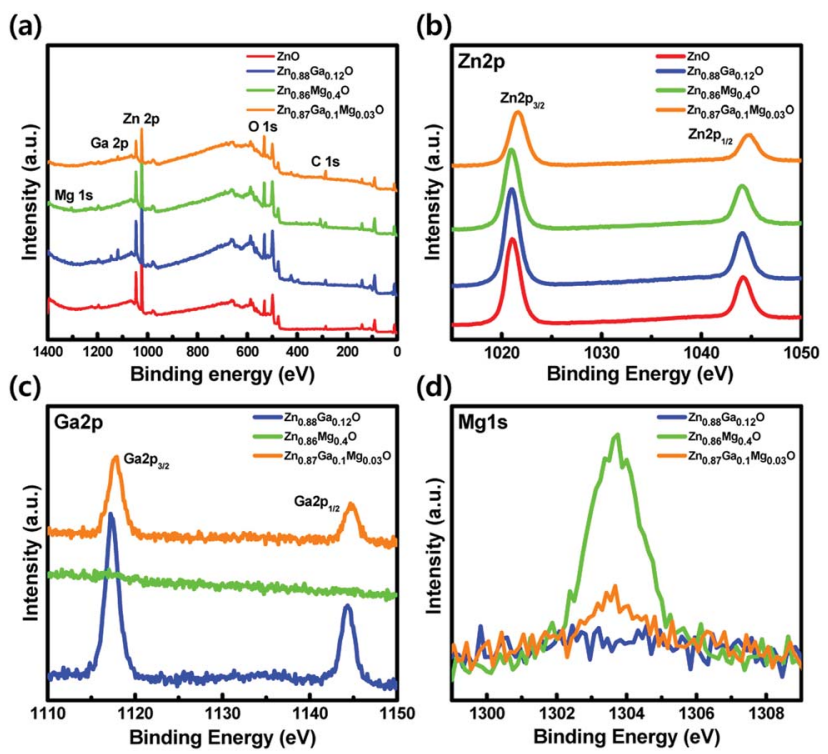

Fig. 2 XPS spectra of $\mathrm{ZnO}, \mathrm{ZnGaO}, \mathrm{ZnMgO}$, and $\mathrm{ZnGaMgO}$ (a) full range XPS spectra (b) XPS spectra of Zn $2 p$ core-level, (c) Ga $2 p$ corelevel, and (d) Mg 1s core-level. replacement of $\mathrm{Zn}^{2+}$ by $\mathrm{Ga}^{3+}$ and/or $\mathrm{Mg}^{2+} \cdot{ }^{\mathbf{1 5 , 1 6}}$ The known electronegativity values of $\mathrm{Mg}, \mathrm{Zn}, \mathrm{Ga}$, and $\mathrm{O}$ atoms are 1.35, 1.65, 1.81, and 3.44, respectively. In the case of ZMO NPs, even though relative difference of electronegativity between $\mathrm{Zn}$ and $\mathrm{O}$ (3.44-1.65) is smaller than that between $\mathrm{Mg}$ and $\mathrm{O}$ (3.44-1.35), the relaxation of $\mathrm{Mg}-\mathrm{O}$ bonding distance up to $2.06 \AA$ longer than $\mathrm{Zn}-\mathrm{O}(1.97 \AA)$ in $\mathrm{Zn}-\mathrm{O}-\mathrm{Mg}$ makes $\mathrm{Zn}$ less electronegative than $\mathrm{Zn}$ in $\mathrm{Zn}-\mathrm{O}-\mathrm{Zn}$. This clearly confirms the shifting of the $\mathrm{Zn}$ 2p XPS peak toward higher binding energy. On the contrary, relative difference of electronegativity between $\mathrm{Zn}$ and $\mathrm{O}$ (3.441.65) is larger than that between $\mathrm{Ga}$ and $\mathrm{O}(3.44-1.81)$, but the contraction of $\mathrm{Ga}-\mathrm{O}$ bonding down to 1.92 A shorter than $\mathrm{Zn}-\mathrm{O}$ (1.97 A) in $\mathrm{Zn}-\mathrm{O}-\mathrm{Ga}$ also makes $\mathrm{Zn}$ less electronegative than $\mathrm{Zn}$ in $\mathrm{Zn}-\mathrm{O}-\mathrm{Zn}$, which further explains the shifting of the $\mathrm{Zn} 2 \mathrm{p}$ to higher energy values. In other words, it can be said that the shifting of the $\mathrm{Zn} 2 \mathrm{p}$ peak is partly effected by the formation of $\mathrm{Zn}-\mathrm{O}-\mathrm{Ga}$ and/or $\mathrm{Zn}-\mathrm{O}-\mathrm{Mg}$ bonds. ${ }^{17,18}$ Fig. 2(c) and (d) show the high-resolution Ga 2p and Mg 1s XPS spectra of ZGO, ZMO, and ZGMO NPs. The Ga 2p peaks of ZGO NPs detected at $1144.37 \mathrm{eV}$ and $1117.42 \mathrm{eV}$ are due to the spin-orbit splitting $\left(\Delta E_{\mathrm{SO}}=26.95\right.$ $\mathrm{eV}$ ) of $\mathrm{Ga} 2 \mathrm{p}_{1 / 2}$ and $\mathrm{Ga} 2 \mathrm{p}_{3 / 2}$ core levels, respectively. A Ga $2 \mathrm{p}$ peak shifts to slightly higher binding energy in ZGMO NPs and this was presumably due to $\mathrm{Mg}^{2+}$ substitution in $\mathrm{Zn}-\mathrm{O}-\mathrm{Ga}-\mathrm{O}-$ $\mathrm{Mg}$ bonds where longer distance of $\mathrm{Mg}-\mathrm{O}$ than $\mathrm{Zn}-\mathrm{O}$ in ZGMO makes Ga less electronegative than $\mathrm{Ga}$ in $\mathrm{ZnGaO}$. However, no remarkable shift of $\mathrm{Mg} 1 \mathrm{~s}$ peak was observed between $\mathrm{ZMO}$ and ZGMO. As shown in Fig. 3, the O 1s peak for ZnO NPs was resolved into three $\mathrm{O}_{\mathrm{I}}(529.6 \mathrm{eV}), \mathrm{O}_{\mathrm{II}}(530.7 \mathrm{eV})$, and $\mathrm{O}_{\mathrm{III}}(531.8$ eV) subpeaks corresponding to $\mathrm{O}_{2}{ }^{-}$ions on the wurtzite structure of the $\mathrm{Zn}^{2+}$ ion array $\mathrm{Zn}-\mathrm{O}$, oxygen vacancy, and surface oxygen like $-\mathrm{OH}$ respectively. ${ }^{\mathbf{9 , 1 9 , 2 0}}$ Relative $\mathrm{O}_{\mathrm{II}}$ ratio decreases by $37.26 \%, 11.46 \%, 14.5 \%$, and $3.03 \%$ in $\mathrm{ZnO}$, ZMO, ZGO, and ZGMO NPs respectively, which indicates the reduction of (a)

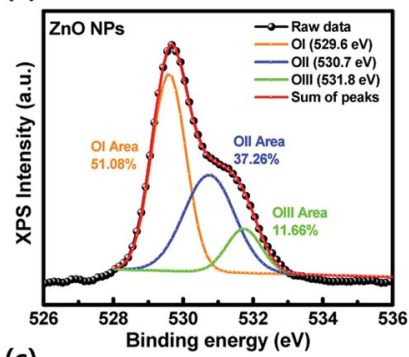

(c)

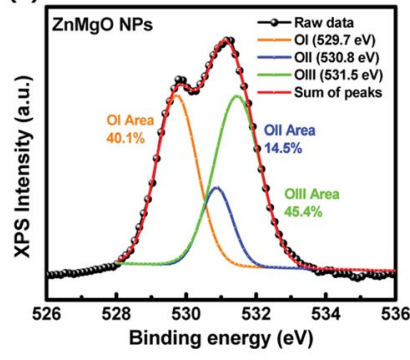

(b)

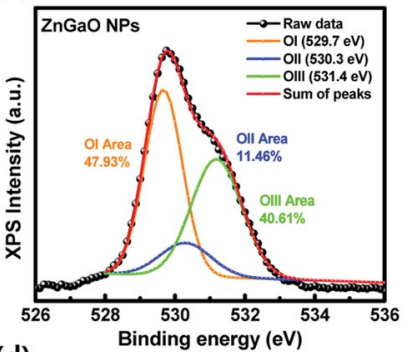

(d)

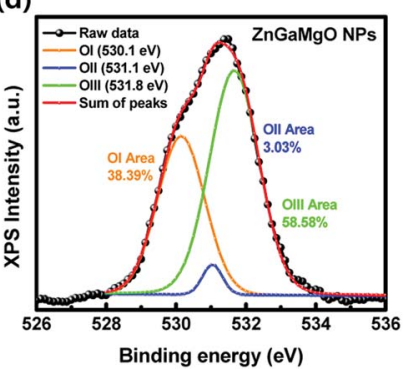

Fig. $3 \mathrm{O}$ 1s core level XPS spectra of (a) $\mathrm{ZnO}$, (b) $\mathrm{ZnGaO}$, (c) $\mathrm{ZnMgO}$, and (d) ZnGaMgO NPs. 
oxygen vacancy defects participating in non-radiative recombination at the interface of ODs/ETLs. Upon $\mathrm{Ga}$ and/or $\mathrm{Mg}$ doping, a slight shift toward higher $\mathrm{O}$ 1s binding energies of $529.7 \mathrm{eV}$ for ZGO and ZMO, and $530.1 \mathrm{eV}$ for ZGMO can be ascribed to the added contribution from $\mathrm{Zn}-\mathrm{O}-\mathrm{Mg}(530.2 \mathrm{eV})$ and $\mathrm{Mg}-\mathrm{O}(530.5-530.8 \mathrm{eV})$ bonds. ${ }^{21,22}$ In Fig. 4(a), the normalized absorbance spectra in UV and visible light region of ZGO, ZMO, and ZGMO NPs are distinctive from ZnO NPs. According to the results obtained, the optical band gaps were calculated to be approximately $3.50 \mathrm{eV}, 3.58 \mathrm{eV}, 3.75 \mathrm{eV}$, and $3.61 \mathrm{eV}$ in $\mathrm{ZnO}$, ZGO, ZMO, and ZGMO NPs, respectively. The band gaps of all doped NPs increases compared to that of un-doped ZnO NPs whereas the band gap of ZMO NPs is the highest, confirming that impurity doping in ZnO NPs results in a blue shift. When $\mathrm{Ga}$ and $\mathrm{Mg}$ are co-doped in ZnO NPs, the band gap value obtained is between the band gap values of ZGO and ZMO NPs. Fig. 4(b) shows the UPS spectra of the valence band edge and secondary electron cut-off regions of ZnO, ZGO, ZMO, and ZGMO NPs films. The work functions (WFs) are calculated from the difference between the incident photon energy $(h v=21.22$ $\mathrm{eV}$ ) and the high binding energy cut-off ( $\left.E_{\text {off }}\right)$. The WFs were approximately measured to be $3.08 \mathrm{eV}, 3.60 \mathrm{eV}, 3.59 \mathrm{eV}$, and $3.51 \mathrm{eV}$, respectively, indicating that WFs in our specimens are much lower than that of typical ZnO films, $\sim 5.2 \mathrm{eV}^{23,24}$ This demonstrates that the Fermi levels are higher than the conduction band minimum (CBM) energy as high as 0.13$0.38 \mathrm{eV}$ and confirms that electronic energy levels are degenerate. The widening of the bandgap in the degenerated semiconductor has been observed and well explained by the

(a)

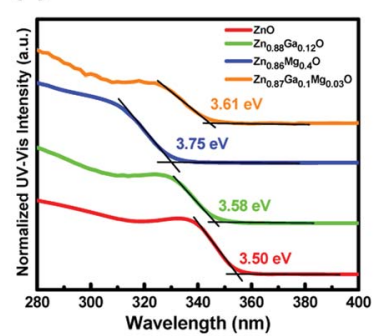

(c)

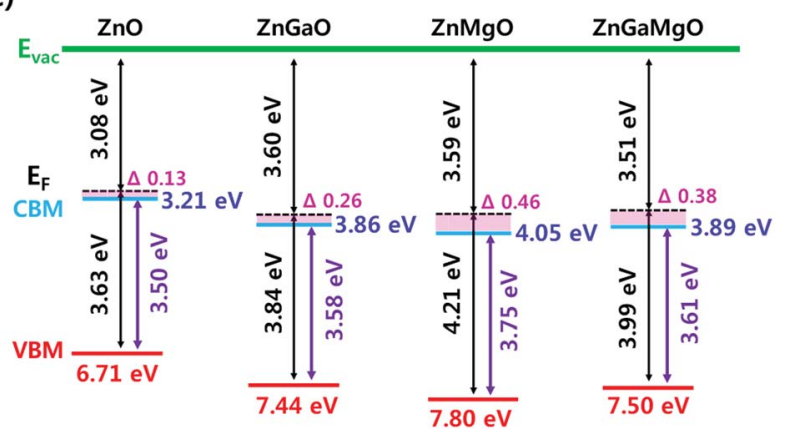

Fig. 4 (a) Normalized UV-Vis absorption spectra of $\mathrm{ZnO}, \mathrm{ZnGaO}$, $\mathrm{ZnMgO}, \mathrm{ZnGaMgO}$ NPs depending on the ratio of each element, respectively. (b) The valence band edge regions and the secondary electron cut-off region via UPS spectra, and (c) corresponding electronic energy level diagrams.
Burstein-Moss (BM) shift equation. ${ }^{25}$ The donor concentration $\left(N_{\mathrm{D}}\right)$ of four materials calculated using the BM shift eqn (1) are: $1.76 \times 10^{19} \mathrm{~cm}^{-3}, 4.99 \times 10^{19} \mathrm{~cm}^{-3}, 1.17 \times 10^{20} \mathrm{~cm}^{-3}$ and 8.83 $\times 10^{19} \mathrm{~cm}^{-3}$ (see the BM shift eqn (1), ESI $\dagger$ ). An increase/ decrease of $N_{\mathrm{D}}$ with different doping ratios are attributed to intrinsic defects (oxygen vacancy or $\mathrm{Zn}$ interstitial) or impurity defects (Ga and/or $\mathrm{Mg}$ elements) varied from un-doped $\mathrm{ZnO}$ NPs. The valence band maximum's (VBMs) for each material are approximately estimated as $6.71 \mathrm{eV}, 7.44 \mathrm{eV}, 7.80 \mathrm{eV}$, and $7.50 \mathrm{eV}$ from the vacuum level. Fig. 4(c) shows the energy band level alignments of four materials with different doping conditions. The optical band gap analyzed in Fig. 4(a) is used to determine the conduction band minimum (CBM). As mentioned in the introduction, the VBM of ZnO NPs is similar to that of green QDs so that ZnO NPs are not likely to act as hole blocking layer (HBL). Furthermore, injection of electrons from the $\mathrm{Al}$ cathode $(4.3 \mathrm{eV})$ into the ETL is constrained since the CBM of ZnO NPs is as low as $3.21 \mathrm{eV}$. The energy band level alignments in Fig. 4(c) apparently present that when $\mathrm{Ga}$ and $\mathrm{Mg}$ are doped into ZnO NPs an injection barrier for electrons between CBM of ETL and Al becomes quite smaller as 0.25$0.44 \mathrm{eV}$ than $1.09 \mathrm{eV}$ in ZnO ETL and the hole blocking barrier between VBM of ETL and VBM of QDs also increases up to 0.94$1.3 \mathrm{eV}$ from $0.21 \mathrm{eV}$ in ZnO ETL and thus effectively blocks holes for charge balance mechanism. Thus, the suggestion in this study could be confirmed to improve the charge recombination efficiency in QD-LEDs. Fig. 5(a) shows a schematic of a fabricated LED device with a typical structure of patterned ITO (anode)/PEDOT:PSS as hole injection layer (HIL)/poly-TPD (HTL)/green QDs as emissive layer (EML)/ZnO, ZGO, ZMO, or ZGMO NPs (ETL or HBL)/Al (cathode). Fig. 5(b)-(e) show energy band diagrams, current density-voltage, luminance, current efficiency $\left(\mathrm{cd} \mathrm{A}^{-1}\right)$, and power efficiency $\left(\mathrm{lm} \mathrm{W}^{-1}\right)$ respectively, of the QD-LEDs device based on ZnO, ZGO, ZMO, and ZGMO NPs. From Fig. 5(b), three kinds of the energy offset $(\Delta G)$ can be considered and are listed in Table $2 . \dagger$ First, an injection barrier $\left(\Delta G_{\text {In }}=\mathrm{CBM}_{\mathrm{ETL}} / \mathrm{Al}\right)$ at the interface between ETLs and $\mathrm{Al}$ electrode, caused by Schottky contact decreases from $1.09 \mathrm{eV}$ for $\mathrm{ZnO}$ to $0.25 \mathrm{eV}$ for ZGMO. The larger $\Delta G_{\text {In }}$, the more improved charge balance and reduced non-radiative Auger recombination. Second, a conduction band offset $\left(\Delta G_{\mathrm{CBM}}\right)$ between the CBM's of ETL and QDs. $\Delta G_{\mathrm{CBM}}$ is varied from $0.99 \mathrm{eV}$ to $0.15 \mathrm{eV}$, which is related to spontaneous electron transfer rate from QDS to ETLs and efficiency. These results verify that the $\mathrm{Ga}$ and $\mathrm{Mg}$ doping of the ZnO NP ETL helps to maintain the charge neutrality of the QD emitters and to preserve their superior emissive properties. Third, there isa valence band offset $\left(\Delta G_{\mathrm{VBM}}\right)$ between the VBM's of ETLs and QDs. $\Delta G_{\mathrm{VBM}}$ increases from $0.21 \mathrm{eV}$ for $\mathrm{ZnO}$ to 1.30 for ZMO ETLs. The deeper $\Delta G_{\mathrm{VBM}}$ will effectively confine hole in QDs and thus enhance the charge recombination efficiency. The current density-voltage $(J-V)$ characteristics in Fig. 5(c) exhibit that the QD-LEDs with ZGO, ZMO, and ZGMO NPs have a lower turn-on voltage of 4.0-4.5 V than $5 \mathrm{~V}$ of $\mathrm{ZnO}$ and the lower current density. Moreover, when dopants are added into ZnO NPs ETL in QD-LEDs luminance, current efficiency, and power efficiency characteristics are more improved compared with un-doped ZnO NPs. As shown in 
(a)

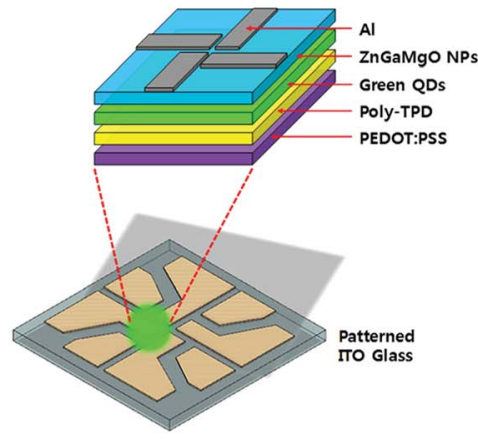

(c)

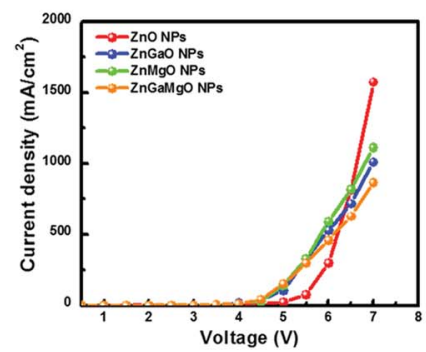

(b)

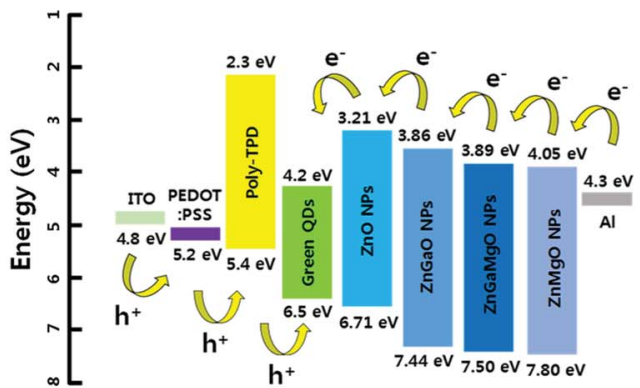

(e)
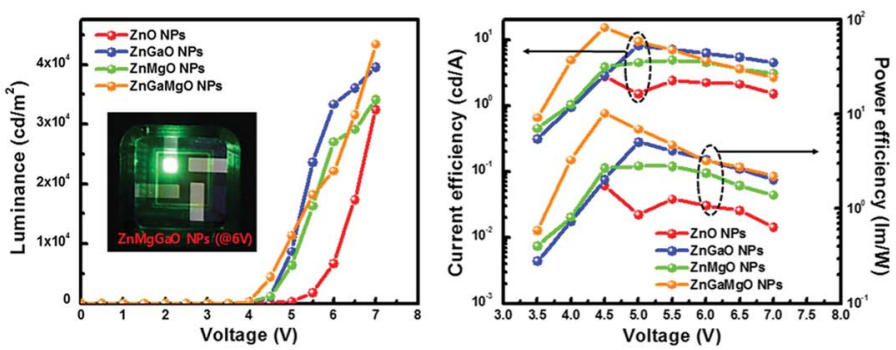

Fig. 5 (a) Schematic 3-dim device structure and (b) flat-band energy diagram of the QD-LEDs device based on $\mathrm{ZnO}, \mathrm{ZnGaO}, \mathrm{ZnMgO}$, and ZnGaMgO NPs. For QD-LEDs with four different ETLs, (c) current density versus voltage, (d) luminance versus voltage, and (e) current efficiency and power efficiency versus voltage curves.

Fig. 5(d) and (e), the device with the ZGMO NPs ETL displays the maximum values of luminance of $43440 \mathrm{~cd} \mathrm{~m}^{-2}$ at $7 \mathrm{~V}$, current efficiency of $15.4 \mathrm{~cd} \mathrm{~A}^{-1}$ at $4.5 \mathrm{~V}$, and power efficiency of $10.3 \mathrm{~lm}$ $\mathrm{W}^{-1}$, which increased by $34 \%$ (luminance), $450 \%$ (current efficiency), and $470 \%$ (power efficiency) compared to those of the device with the ZnO NPs ETL $\left(32480 \mathrm{~cd} \mathrm{~m}^{-2}\right.$ at $7 \mathrm{~V}, 2.8 \mathrm{~cd} \mathrm{~A}^{-1}$, $4.5 \mathrm{~V}$, and $1.8 \mathrm{~lm} \mathrm{~W}^{-1}$ ). In terms of luminance, current efficiency, and power efficiency results, the barrier heights of $\Delta G_{\mathrm{CBM}}=0.31 \mathrm{eV}$ and $\Delta G_{\mathrm{CBM}}=1.0 \mathrm{eV}$ in ZGMO are believed to be the most optimum condition for charge neutrality of QDs for a facilitative electron injection at interface of ETL/Al and an effectively limited hole migration. The inset in Fig. 5(d) presents an emission photographic image of QD-LEDs based on the ZGMO NPs as ETL, acquired at a voltage of $6 \mathrm{~V}$. To reduce nonradiative recombination and increase the device efficiency, it is critical to engineer the charge transport layers to achieve balanced charge transport and low leakage currents. ${ }^{26-28}$ In order to confirm the charge transfer effect of doped Ga and/or $\mathrm{Mg}$ elements in ZnO NPs on electron-only devices, devices of ITO/ETL (ZnO, ZGO, ZMO, and ZGMO NPs)/green QDS/ETL (ZnO, ZGO, ZMO, and ZGMO NPs)/Al were fabricated as shown in Fig. 6(a). As shown in Fig. 6(b) it is revealed that current density decreases as $\mathrm{Ga}$ and $\mathrm{Mg}$ elements are incorporated and shows the lowest value in the QD-LEDs with ZGMO ETLs. It is well known that the conductivity of ZnO depends on the concentration of oxygen vacancies, because oxygen vacancies can help improve the electron mobility. ${ }^{29,30}$ Therefore, these results confirm that the incorporation of $\mathrm{Ga}, \mathrm{Mg}$ dopants into ZnO NP ETLs is an effective means of reducing non-radiative charge recombination and consequently, enhancing the efficiency of QD-LED devices. This result indicates that the conductivity of ZGMO is lower than that of the other ZGO and ZMO ETL materials.
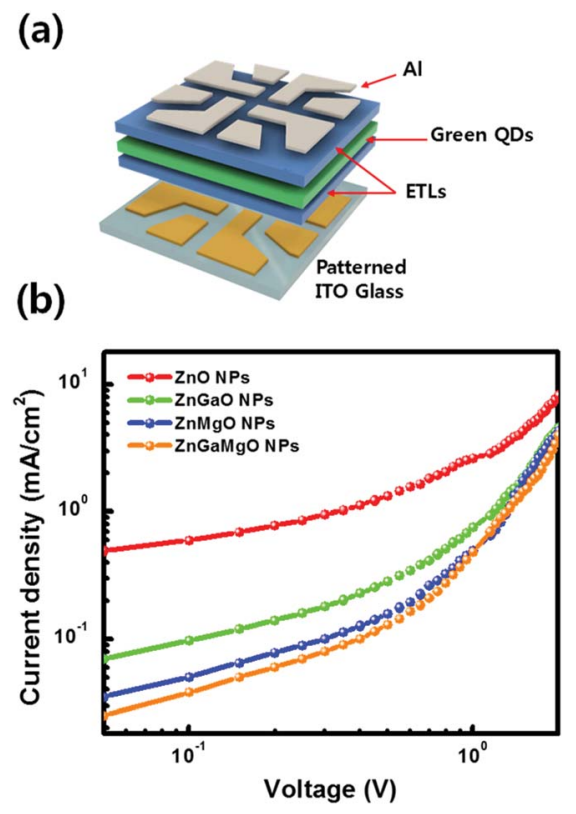

Fig. 6 (a) A schematic image of an electron-only QD-LEDs using a $\mathrm{ZnO}, \mathrm{ZnGaO}, \mathrm{ZnMgO}$, and $\mathrm{ZnGaMgO} \mathrm{NPs}$ as ETLs and (b) their characteristic current density-voltage $(J-V)$ curves. 


\section{Conclusions}

In conclusion, we have optimized electron-hole balance of QDLEDs by using Ga-Mg-codoped ZnO NPs as ETL. The Ga-Mgcodoped ZnO NPs improved charge balance and reduced nonradiative Auger recombination in QD-LEDs. In addition, the performance of QD-LEDs is improved by minimizing the oxygen vacancy of $\mathrm{ZnO}$ NPs and thus lowering leakage current. As a results, the $L_{\max }$ and $L E_{\text {max }}$ of QD-LEDs based on ZGMO NPs reach $43440 \mathrm{~cd} \mathrm{~m}^{-2}$ and $15.4 \mathrm{~cd} \mathrm{~A}^{-1}$. These results are increased by $34 \%, 10 \%$ and $27 \%$ for the $L_{\max }$ and $450 \%, 88 \%$, and $208 \%$ for the $\mathrm{LE}_{\max }$ when compared with $\mathrm{ZnO}$, ZGO, and ZMO NPs as ETL. It is therefore reasonable to conclude that Ga and $\mathrm{Mg}$ co-doping of $\mathrm{ZnO}$ is more effecting in improving electron transport compared individual doping of $\mathrm{Ga}$ and $\mathrm{Mg}$.

\section{Conflicts of interest}

There are no conflicts of interest to declare.

\section{Acknowledgements}

This work was supported by Korea Institute of Science and Technology (KIST) Institutional Program under Contract No. 2E28200 and South Africa/South Korea joint collaboration programmed managed by National Research Foundation, (Grant No. 2014K1A3A1A09063246/SKO15081792426)

\section{References}

1 L. Sun, J. J. Choi, D. Stachnik, A. C. Bartnik, B.-R. Hyun, G. G. Malliaras, T. Hanrath and F. W. Wise, Nat. Nanotechnol., 2012, 7, 369.

2 K.-H. Lee, J.-H. Lee, W.-S. Song, H. Ko, C. Lee, J.-H. Lee and H. Yang, ACS Nano, 2013, 7, 7295-7302.

3 K. Qasim, B. Wang, Y. Zhang, P. Li, Y. Wang, S. Li, S.-T. Lee, L.-S. Liao, W. Lei and Q. Bao, Adv. Funct. Mater., 2017, 27, 1606874.

4 L. Wang, J. Pan, J. Qian, W. Lei, Y. Wu, W. Zhang, D. K. Goto and J. Chen, J. Mater. Chem. C, 2018, 6, 8099-8104.

5 S. Cao, J. Zheng, J. Zhao, Z. Yang, C. Li, X. Guan, W. Yang, M. Shang and T. Wu, ACS Appl. Mater. Interfaces, 2017, 9, 15605-15614.

6 Y. Sun, Y. Jiang, H. Peng, J. Wei, S. Zhang and S. Chen, Nanoscale, 2017, 9, 8962-8969.

7 K. Tvrdy, P. A. Frantsuzov and P. V. Kamat, Proc. Natl. Acad. Sci. U. S. A., 2011, 108, 29-34.

8 W. H. Cheng, J. W. Chiou, M. Y. Tsai, J. S. Jeng, J. S. Chen, S. L. C. Hsu and W. Y. Chou, J. Phys. Chem. C, 2016, 120, 15035-15041.

9 Y. J. Lee, H. H. Kim, Y. J. Lee, J. H. Kim, H.-J. Choi and W. K. Choi, Nanotechnology, 2019, 30, 035207.
10 J.-H. Kim, C.-Y. Han, K.-H. Lee, K.-S. An, W. Song, J. Kim, M. S. Oh, Y. R. Do and H. Yang, Chem. Mater., 2015, 27, 197-204.

11 H. H. Kim, Y. J. Lee, C. Park, S. Yu, S. O. Won, W.-S. Seo, C. Park and W. K. Choi, Part. Part. Syst. Charact., 2018, 1800080.

12 H. M. Xiong, D. G. Shchukin, H. Mohwald, Y. Xu and Y. Y. Xia, Angew. Chem., Int. Ed., 2009, 48, 2727-2731.

13 X. Liang, Y. Ren, S. Bai, N. Zhang, X. Dai, X. Wang, H. He, C. Jin, Z. Ye, Q. Chen, L. Chen, J. Wang and Y. Jin, Chem. Mater., 2014, 26, 5169-5178.

14 R. D. Shannon, Acta Crystallogr., Sect. A: Cryst. Phys., Diffr., Theor. Gen. Crystallogr., 1976, 32, 751.

15 C. J. Ku, W. C. Hong, T. Mohsin, R. Li, Z. Q. Duan and Y. C. Lu, IEEE Electron Device Lett., 2015, 36, 914-916.

16 X. Zhang, L. Li, J. Su, Y. Wang, Y. Shi, X. Ren, N. Liu, A. Zhang, J. Zhou and Y. Gao, Laser Photonics Rev., 2014, 8, 429-435.

17 M. K. Hamza, J. M. Bluet, K. Masenelli-Varlot, B. Canut, O. Boisron, P. Melinon and B. Masenelli, Nanoscale, 2015, 7, 12030-12037.

18 E. Della Gaspera, A. S. R. Chesman, J. van Embden and J. J. Jasieniak, ACS Nano, 2104, 8, 9154-9163.

19 S. S. Hullavarad, N. V. Hullavarad, D. E. Pugel, S. Dhar, T. Venkatesan and R. D. Vispute, Opt. Mater., 2008, 30, 993. 20 D. W. Langer and C. J. Vesely, Phys. Rev. B: Solid State, 1970, 2, 4885 .

21 V. I. Nefeddov, M. N. Firsov and I. S. J. Shaplygin, J. Electron Spectrosc. Relat. Phenom., 1982, 26, 625.

22 A. Le Febvrier, J. Jensen and P. Eklund, J. Vac. Sci. Technol., A, 2017, 35, 021407.

23 J. Xiao, X. X. Zhang and G. M. Zhang, Nanotechnology, 2008, 19, 295706.

24 J. B. You, X. W. Zhang, P. F. Cai, J. J. Dong, Y. Gao, Z. G. Yin, N. F. Chen, R. Z. Wang and H. Yan, Appl. Phys. Lett., 2009, 94, 262105.

25 C. E. Kim, P. Moon, S. Kim, J.-M. Myoung, H. W. Jang, J. Bang and I. Yun, Thin Solid Films, 2010, 518, 6304-6307.

26 X. Dai, Z. Zhang, Y. Jin, Y. Niu, H. Cao, X. Liang, L. Chen, J. Wang and X. Peng, Nature, 2014, 515, 96-99.

27 J. Pan, J. Chen, Q. Huang, Q. Khan, X. Liu, Z. Tao, Z. Zhang, W. Lei and A. Nathan, ACS Photonics, 2016, 3, 215-222.

28 S. Cao, J. Zheng, J. Zhao, Z. Yang, C. Li, X. Guan, W. Yang, M. Shang and T. Wu, ACS Appl. Mater. Interfaces, 2017, 9, 15605-15614.

29 K. Nomura, H. Ohta, A. Takagi, T. Kamiya, M. Hirano and H. Hosono, Nature, 2004, 432, 488.

30 E. Fortunato, P. Barquinha and R. Martins, Adv. Mater., 2012, 24, 2945-2986. 